\section{Dartford-Purfleet Tunnel}

Besow Blackwall tunnel, which is thirty-five miles from the mouth of the Thames estuary, there are no facilities for crossing the Thames either by bridge or tunnel. The construction has now been approved of a tunnel, which will be called the Dartford-Purffeet tunnel and will connect the Purfleet-Grays Road on the north side of the river with the Dartford Southern by-pass, and a connexion will then be made with the London-Folkestone and the London-Hastings roads. As a first step (Roads and Road Construction, Septem. ber 1), a pilot tunnel will be constructed 900 yards in length and with an internal diameter of 12 feet. Two ventilating shafts with diameters of 18 feet will be constructed on the Kent and Essex banks of the river. They will be approximately 100 feet in depth. The pilot tunnel will cost $£ 300,000$ and will provide information as to the strata under the river at this place. This will be very helpful in connexion with the construction of the main tunnel. The tunnel will be rather more than a mile in length. The cost of the whole scheme is estimated to be about three million pounds, the pilot tunnel costing about a tenth of this. The Ministry of Transport, which will be directly responsible for carrying out the work, has made, in conjunction with the county councils of Essex and Kent, all the necessary arrangements. This tunnel, which will be twelve miles down the river from the Blackwall tunnel, will form a much-needed link between the north and south sides of the Thames Estuary.

\section{Electrical Accidents in 1935}

THE report on electrical accidents in 1935 by H.M. electrical inspector of factories (London: H.M. Stationery Office. 9d.) is of special value to all who design and operate electrical apparatus. The total number of accidents reported under the Acts was 447 , of which 23 were fatal. Although the use of electricity has doubled during the last ten years, the annual total of the number of accidents has varied very little. The total number, twenty-three, of fatal accidents on factory premises is eight less than last year. This is probably due to the much larger use now made of artificial respiration when attempting to revive the victims of electric shock. In successful cases the time of application necessary varied from a few minutes to half an hour. Last year there were nine successful cases, but if it had been tried in every case there would doubtless have been more, as signs of life in some of the cases which ended fatally were evident after the shock. The inspectors specially mention the very rapid growth of electric arc welding to structures of all kinds. Although there were thirty-six electrical accidents to electrical welders, none of them was fatal. This is probably largely due to the attention now being paid to the personal equipment of the operator. Gauntlets, hand sereens and helmets are made of suitable insulating materials, and are standardized. In addition, the harmful effects produced on the eyes of workmen not concerned in the welding processes, but liable to flashes from an arc in their vicinity, are considered. It has been found that plain glasses cut off a large pro- portion of the harmful ultra-violet rays. Until they had experienced the painful effects of eye flash, workmen were reluctant to wear them; in works where they are used, eye trouble has been eliminated.

\section{New Conceptions of a Rock Garden}

ENGLISH gardens have been enriched with many beautiful herbaceous plants from South Africa, but the succulent and xerophytic species of that region are not yet common in England. The rockery which is being made in Johannesburg for the Empire Exhibition of September, 1936-January, 1937 should provide an adequate portrayal of South Africa's wonderful endowments in these sections of its flora. Prof. John Phillips, professor of botany in the University of the Witwatersrand, describes the rockery in the Journal of the Royal Horticultural Society of August, 1936. It is planned upon a scale which is somewhat gigantic when judged from most English standards. Summits are broken with plantings of Aloe Marlothii, A. dichotoma, and other species, whilst the most striking effects are produced by the mesembryanthemums, the euphorbias, members of the genus Encephalartos, the pelargoniums, and by Aster capensis, Dimorphotheca Ecklonis and Euryops athanasia. A stream, rushing from the rock garden into the lake below, affords opportunity for the planting of indigenous hygrophilous plants, and lawns of Cynodon sp. and Pennisetum clandestinum have been laid. Large woody shrubs, and even small trees, such as Chilianthus arboreus, Rhus lancea, Dombeya rotundifolia, Cussonia spicata, Tecomaria capensis, Plumbago capensis, and other species, are employed for certain effects. Mr. Frank Frith, an expert on succulents, is supervising the making of the rockery.

\section{Early Man in Colorado-Further Investigations}

Early in June, Dr. Frank H. H. Roberts, jun., of the Smithsonian Institution, Washington, D.C., resumed excavations on the Lindenmeier site in northern Colorado for the third consecutive summer (see Nature, Oct. 5, 1935, p. 535). While this habitation or camp site of Folsom man, the only known site of its kind and the only source of more than isolated specimens of the characteristic grooved stone Folsom point, has produced an abundance of evidence of the mode of life of Folsom man, hitherto no human skeletal remains have been found in association with this culture. Dr. Roberts's investigations during the coming season, therefore, will be devoted especially to the search for human skeletal remains. That early man was a contemporary of the extinct forms of bison found on the Lindenmeier site and dating possibly from the last stages of the Ice Age, is incontestable, as the tip end of a point was discovered in the foramen of the spinal column of a bison, of which a considerable portion of the skeleton was uncovered with the bones still articulated. A further matter of interest is that the palæontological evidence obtained by Dr. Roberts points to a climate somewhat warmer than that of the present day, some of the invertebrates represented by fossils being considerably north of their present range. 